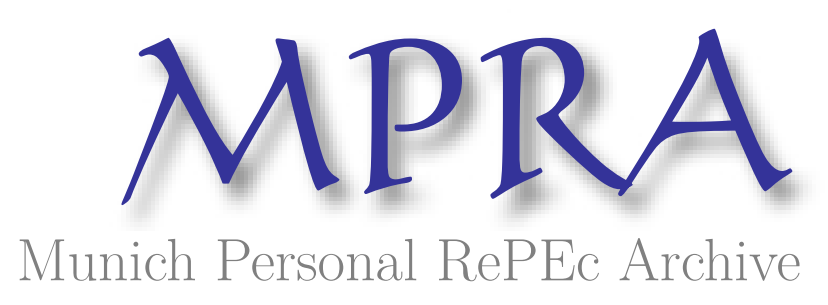

\title{
Inflation and Fertility in a Schumpeterian Growth Model: Theory and Evidence
}

He, Qichun

Central University of Finance and Economics

March 2018

Online at https://mpra.ub.uni-muenchen.de/85074/

MPRA Paper No. 85074, posted 13 Mar 2018 06:18 UTC 


\title{
Inflation and Fertility in a Schumpeterian Growth Model: Theory and Evidence*
}

\author{
Qichun $\mathrm{He}^{\dagger}$ \\ (Central University of Finance and Economics, Beijing, China) \\ 2018
}

\begin{abstract}
This study explores a novel channel for monetary policy to impact growth and welfare - through fertility choice. In a scale-invariant Schumpeterian growth model with endogenous fertility and a cash-in-advance constraint on consumption, we find a positive effect of an increase in the nominal interest rate on fertility. The increase in fertility decreases labor supplied to production and R\&D, which in turn decreases long-run growth. Calibration shows that long-run growth increases $0.12 \%$ by reducing the nominal interest rate from $9.6 \%$ to $0 \%$, and the welfare gain is equivalent to a permanent increase in consumption of $3.14 \%$. As an empirical test, we build panel data for 12 advanced countries during 2000-2014. We use the degree of central bank independence and money growth as the instruments for inflation. We find that the effect of inflation on population growth is positive and significant in instrumental variables estimation. Our results remain robust to using birth rate or fertility rate as the dependent variable. An increase in annual inflation of 1 percentage point would bring an increase of 0.06 percentage point in the annual growth of the total population. Our empirical findings provide support for our theory.
\end{abstract}

JEL Classification: O31, O42, J1

Keywords: Monetary policy; fertility; economic growth; panel data

*I am grateful to Angus Chu for comments that substantially improved the paper. I also thank Robert Inklaar for kind explanation on the Penn World Table 9.0 data. I am also grateful to "the Fundamental Research Funds for the Central Universities" for language editing. All the errors are mine.

†Email: qichunhe@gmail.com, heqichun@cufe.edu.cn. 


\section{Introduction}

Researchers have studied many issues concerning fertility (discussed below). In this paper we reveal a novel channel - fertility choice - through which monetary policy may impact growth and welfare. It may sound counter-intuitive to investigate the effect of monetary policy on population growth (i.e., to link people's fertility choice to monetary policy). However, if humans were rational, they would also optimize their fertility decision together with the other choices such as consumption and investment. In a scale-invariant Schumpeterian growth model with endogenous fertility and a cash-in-advance (CIA) constraint on consumption, we find that an increase in the nominal interest rate has a positive effect on fertility, which in turn decreases long-run growth. As an empirical test, we build panel data for 12 advanced countries during 2000-2014. We find that inflation has a significant, positive effect on population growth in instrumental variables (IV) estimation, which provides support for our theory. The motivation of our paper is as follows.

First, our study offers a novel channel - fertility choice/population growth - for monetary policy to impact economic growth and social welfare. Population growth is assumed to be exogenous within the existing R\&D-driven growth-theoretic framework (e.g., Marquis and Reffett, 1994; Chu and Cozzi, 2014; Chu et al., 2015; Chen, 2015; He, 2015; Huang et al., 2015; Chu et al., 2016; Chu et al., 2017; Chu et al., 2018). The only exception is Chu, Cozzi, and Liao (2013), who have endogenized fertility choice and human capital accumulation in Schumpeterian growth models. Our study complements theirs by further analyzing the effect of monetary policy on fertility choice. Doing so reveals that monetary policy may have an impact on people's fertility choice, which in turn affects long-run growth and welfare. Therefore, our study helps us to understand the entire mechanism through which monetary policy may impact long-run growth and welfare.

Second, our study helps in understanding the long-run dynamics of total population. In many studies total population growth is regarded as exogenous (e.g., population growth is treated as an exogenous instrument for international trade in evaluating its causal effect on income; see discussion in Frankel and Romer, 1999). Researchers have investigated many issues related to fertility. For instance, Li, Zhang, and Zhu (2008) and Rosenzweig and Zhang (2009) have tested the quantity-quality trade-off in having children. The unified growth framework has endogenized people's fertility in explaining the long-run growth and population dynamics (e.g., Galor and Mountfold, 2008; Strulik and Weisdorf, 2008). Our study complements the existing studies by endogenizing people's fertility within a Schumpeterian growth framework, similar to Chu, Cozzi, and Liao (2013). However, in existing studies, the role of monetary policy is ignored. Considering monetary policy is important because there is always a trade-off between consumption and raising children when parents are rational. Monetary policy is one important exogenous factor that may 
impact the trade-off faced by each rational individual. Moreover, by taking our model to data, we can test the effect of the inflation rate (a proxy for monetary policy) on the fertility rate to check the validity of our theory and further evaluate the importance/magnitude of the channel that we emphasize. In other words, we can also evaluate how much our channel (the monetary policy) can explain total population growth. This not only helps us to understand the long-run dynamics of the total population but also has rich policy implications.

The intuition of our results is as follows. We introduce money via a CIA constraint on consumption into a Schumpeterian growth model, following Chu and Cozzi (2014). With exogenous population growth, the nominal interest rate has no effect on economic growth when there is an inelastic labor supply (see also Chu and Cozzi, 2014). With an inelastic labor supply, a higher nominal interest rate would not distort the labor supply through consumption-leisure choice (i.e., the choice for leisure is absent). When the CIA constraint applies only on consumption (i.e., not on R\&D labor or manufacturing), a higher nominal interest would not distort the allocation of labor between manufacturing and $\mathrm{R} \& \mathrm{D}$, leaving the balanced growth rate unaffected. In contrast, with endogenizing fertility choice, in choosing optimal fertility, households equate the marginal utility of fertility to the marginal cost of fertility. The marginal cost of fertility consists of three terms: the asset-diluting effect of fertility, the foregone-wage effect of fertility, and the real money balance-diluting effect, all of which depend negatively on the nominal interest rate due to the CIA constraint on consumption. Therefore, all else being equal, a higher nominal interest rate decreases the marginal cost of fertility and thereby increases fertility. In other words, a higher nominal interest rate and thereby a higher inflation rate via the CIA constraint on consumption makes fertility cheaper relative to consumption, thus increasing fertility. The increase in fertility decreases the amount of labor supplied to production and $\mathrm{R} \& \mathrm{D}$, leading to a decreased long-run growth.

We calibrate the model to estimate the growth and welfare effects of a change in the nominal interest rate. We find that long-run growth increases $0.12 \%$ by reducing the nominal interest rate from $9.6 \%$ (the sample mean, elaborated below) to $0 \%$. The corresponding welfare gain is equivalent to a permanent increase in consumption of $3.14 \%$. As a counterfactual, we find that the growth and welfare losses are smaller when people prefer more children. Additionally, there are substantial growth and welfare losses when people's preference for children increases, all else being equal.

As an empirical test, we build panel data for 12 advanced countries during 20002014. We use the degree of central bank independence (CBI) and money growth as the instruments for inflation. We find the following. The effect of inflation on population growth is positive and significant in IV estimation. Our results remain robust to using birth rate or fertility rate as the dependent variable. Our empirical findings provide 
support for our theory. Additionally, we find that an increase in annual inflation of one percentage point would bring an increase of 0.06 percentage points in annual growth of the total population. Given the average annual inflation rate of $2.71 \%$ in our data sample, inflation explains $0.17 \%$ annual growth in the total population (approximately $20 \%$ of the average $0.89 \%$ annual growth rate in total population in the 12 advanced economies during 2000-2014). Therefore, the magnitude of the estimated effect of inflation on total population growth is large.

This study relates to the large body of literature on fertility/population growth and its effect on the economy (see Nishimura and Zhang, 1992; Davies and Zhang, 1997, and references therein).

The rest of this paper is organized as follows. Section 2 sets up the monetary Schumpeterian growth model to analyze the fertility and growth effects of monetary policy. Section 3 provides the empirical evidence. The final section concludes the paper.

\section{A Monetary Schumpeterian Model with Endoge- nous Fertility}

Built on existing studies (e.g., Chu and Cozzi, 2014; He and Zou, 2016), we introduce money with a CIA constraint on consumption into a Schumpeterian growth model.

\subsection{Households}

There is a unit continuum of identical households. At time $t$, the population size of each household is $L_{t}$. There is a unit continuum of identical households, which have a lifetime utility function as

$$
U=\int_{0}^{\infty} e^{-\rho t}\left[\ln \left(c_{t}\right)+\theta \ln \left(n_{t}\right)\right] d t,
$$

where $c_{t}$ is per capita real consumption of final goods (numeraire) and $n_{t}$ is the per capita number of births at time $t . \quad \rho>0$ is the rate of time preference, and $\theta>0$ governs people's preference for children. Following Chu et al. (2013), we assume zero mortality. Therefore, the population growth rate is also $n_{t}$ (i.e., $L_{t} / L_{t}=n_{t}$ ).

Each household maximizes its lifetime utility given in equation (1) subject to the asset-accumulation equation given by

$$
\dot{a}_{t}+\dot{m}_{t}=\left(r_{t}-n_{t}\right) a_{t}+w_{t}\left(1-\frac{n_{t}}{\xi}\right)-c_{t}-\left(\pi_{t}+n_{t}\right) m_{t}+\tau_{t},
$$

where $a_{t}$ is the real value of equity shares in monopolistic intermediate goods firms owned by each member of households; $r_{t}$ and $w_{t}$ are the rate of real interest and wage, respectively. Each person has one unit of time endowment to allocate between work and fertility. The 
time used in raising children is given by $n_{t} / \xi<1$, where $\xi$ is a parameter measuring the time cost of raising children (following Chu et al., 2013). $c_{t}$ is per capita consumption. $m_{t}$ is the real money balance held by each person, and $\pi_{t}$ is the cost of holding money (i.e., the inflation rate). In (2), each person also receives a per capita lump-sum transfer of the seigniorage revenue $\tau_{t}$ from the government (or pay a lump-sum tax if $\tau_{t}<0$ ). The CIA constraint is given by $c_{t} \leq m_{t}$.

The no-arbitrage condition is $i_{t}=\pi_{t}+r_{t}$, where $i_{t}$ is also the nominal interest rate. Standard dynamic optimization (see the Appendix) yields the optimality condition for consumption as

$$
\frac{1}{c_{t}}=\mu_{t}\left(1+i_{t}\right)
$$

where $\mu_{t}$ the Hamiltonian co-state variable on (2). The intertemporal optimality condition is

$$
-\frac{\dot{\mu_{t}}}{\mu_{t}}=r_{t}-n_{t}-\rho
$$

The optimality condition for fertility is

$$
\frac{\theta}{n_{t}}=\mu_{t}\left(a_{t}+\frac{w_{t}}{\xi}+m_{t}\right) .
$$

\subsection{Final-Goods Sector}

The final-goods sector is competitive. The production function of the final-goods firms is given by

$$
y_{t}=\exp \left(\int_{0}^{1} \ln x_{t}(j) d j\right),
$$

where $x_{t}(j)$ denotes intermediate goods $j \in[0,1]$. The final goods firms maximize their profit, taking the price of each intermediate good $j$, denoted $p_{t}(j)$, as given. The demand function for $x_{t}(j)$ is

$$
x_{t}(j)=y_{t} / p_{t}(j)
$$

\subsection{Intermediate-Goods Sector}

As clearly elaborated in Chu and Cozzi (2014), there is a unit continuum of industries producing differentiated intermediate goods. Each industry is temporarily dominated by an industry leader until the arrival of the next innovation, and the owner of the new innovation becomes the next industry leader. The leader in industry $j$ has the following production function:

$$
x_{t}(j)=\gamma^{q_{t}(j)} L_{x, t}(j) .
$$


The parameter $\gamma>1$ is the step size of an improvement in productivity, and $q_{t}(j)$ is the number of productivity improvements that have occurred in industry $j$ as of time $t$. $L_{x, t}(j)$ is the production labor in industry $j$. Equation (8) adopts a cost-reducing view of vertical innovation, as pointed out by Chu and Cozzi (2014). Given $\gamma^{q_{t}(j)}$, the marginal cost of production for the industry leader in industry $j$ is $m c_{t}(j)=w_{t} / \gamma^{q_{t}(j)}$.

Standard Bertrand price competition leads to a profit-maximizing price $p_{t}(j)$ determined by a markup $\gamma$ (the step size of innovation) over the marginal cost. The amount of monopolistic profit is

$$
\Pi_{t}(j)=\left(\frac{\gamma-1}{\gamma}\right) p_{t}(j) x_{t}(j)=\left(\frac{\gamma-1}{\gamma}\right) y_{t} .
$$

The labor income from production is

$$
w_{t} L_{x, t}(j)=\left(\frac{1}{\gamma}\right) p_{t}(j) x_{t}(j)=\left(\frac{1}{\gamma}\right) y_{t} .
$$

\subsection{Research Arbitrage}

Research arbitrage is similar to Chu and Cozzi (2014). In a symmetric equilibrium, we have $\Pi_{t}(j)=\Pi_{t}$. We denote $v_{t}(j)$ as the value of the monopolistic firm in industry $j$. In a symmetric equilibrium, $v_{t}(j)=v_{t}$. The no-arbitrage condition for $v_{t}$ is

$$
r_{t} v_{t}=\Pi_{t}+\dot{v}_{t}-\lambda_{t} v_{t}
$$

Equation (11) says that the return on holding an innovation, $r_{t} v_{t}$, equals the sum of the flow profit of innovation, $\Pi_{t}$, and potential capital gain $\left(\dot{v}_{t}\right)$, less the expected capital loss, $\lambda_{t} v_{t}$, where $\lambda_{t}$ is the arrival rate of the next innovation.

Following Chu and Cozzi (2014), the zero-expected-profit condition of R\&D firm $k \in$ $[0,1]$ in each industry is

$$
\lambda_{t}(k) v_{t}=w_{t} L_{r, t}(k)
$$

where $L_{r, t}(k)$ is the amount of labor hired by R\&D firm $k$, and the firm-level innovation rate per unit time (i.e., $\left.\lambda_{t}(k)\right)$ is $\lambda_{t}(k)=\frac{\varphi}{L_{t}} L_{r, t}(k)$, where $\varphi$ is a constant. This assumption is made to remove the scale effect of total population on steady-state growth (see also Chu and Cozzi, 2014; Laincz and Peretto, 2006). The aggregate arrival rate of innovation is

$$
\lambda_{t}=\int_{0}^{1} \lambda_{t}(k) d k=\frac{\varphi}{L_{t}} N_{r, t}=\varphi l_{r, t},
$$

where we define a transformed variable $l_{r, t} \equiv L_{r, t} / L_{t}$ (the share of R\&D labor in total population). Similarly, the share of production labor would be $l_{x, t}=L_{x, t} / L_{t}$. 


\subsection{Monetary Authority}

The monetary authority exogenously chooses the monetary growth rate $\dot{M}_{t} / M_{t}$. It is equivalent to the case in which the nominal interest rate is chosen as the policy instrument because $i_{t}=M_{t} / M_{t}+\rho$. The derivation is as follows. We have $m_{t}=M_{t} /\left(P_{t} L_{t}\right)$, where $P_{t}$ is the price of final goods and $\dot{P}_{t} / P_{t}=\pi_{t}$. Therefore, we have $\dot{m}_{t} / m_{t}=\dot{M}_{t} / M_{t}-\dot{P}_{t} / P_{t}-n_{t}$. On the balanced growth path, $m_{t}$ and $c_{t}$ grow at the same rate $g_{t}$. Using equation (4), we have $g_{t}=r_{t}-n_{t}-\rho$. Taken together, we have $\dot{M}_{t} / M_{t}-\dot{P}_{t} / P_{t}-n_{t}=r_{t}-n_{t}-\rho$. Given $i_{t}=\pi_{t}+r_{t}$, we have $i_{t}=\dot{M}_{t} / M_{t}+\rho$.

\subsection{General Equilibrium}

As in Chu and Cozzi (2014), the general equilibrium is a time path of prices $\left\{p_{t}(j), r_{t}, w_{t}, i_{t}, v_{t}\right\}$ and allocations $\left\{c_{t}, m_{t}, n_{t}, y_{t}, x_{t}(j), L_{x, t}(j), L_{r, t}(k)\right\}$, which satisfy the following conditions at each instance of time:

- households maximize utility taking prices $\left\{r_{t}, w_{t}, i_{t}\right\}$ as given;

- competitive final-goods firms maximize profit taking $\left\{p_{t}(j)\right\}$ as given;

- monopolistic intermediate-goods firms choose $\left\{L_{x, t}(j), p_{t}(j)\right\}$ to maximize profit taking $\left\{w_{t}\right\}$ as given;

- R\&D firms choose $\left\{L_{r, t}(k)\right\}$ to maximize expected profit taking $\left\{w_{t}, i_{t}, v_{t}\right\}$ as given;

- the labor market clears (that is, $L_{x, t}+L_{r, t}=L_{t}\left(1-\frac{n_{t}}{\xi}\right)$ );

- the final-goods market clears (that is, $y_{t}=c_{t} L_{t}$ );

- the value of monopolistic firms adds up to the value of households' assets (i.e., $\left.v_{t}=a_{t} L_{t}\right)$.

- the CIA constraint binds: $c_{t}=m_{t}$.

\subsection{Balanced Growth Path}

Because balanced growth rate is pinned down by the share of labor employed by R\&D firms, we solve for the equilibrium labor allocation. The equilibrium labor allocation is stationary on a balanced growth path. Using conditions $\dot{v}_{t} / v_{t}=g+n, \lambda \Pi_{t}=(\rho+\lambda) w_{t} L_{r, t}$, (9), (10), (12), and (13), we end up with

$$
(\gamma-1) l_{x}=\left(l_{r}+\rho / \varphi\right)
$$


The labor market clearing condition is

$$
l_{r}+l_{x}=1-\frac{n}{\xi}
$$

Solving (14)-(15) yields the equilibrium labor allocation as

$$
\begin{aligned}
& l_{r}=\frac{(\gamma-1)}{\gamma}\left(1-\frac{n}{\xi}+\frac{\rho}{\varphi}\right)-\frac{\rho}{\varphi} \\
& l_{x}=\frac{1}{\gamma}\left(1-\frac{n}{\xi}+\frac{\rho}{\varphi}\right)
\end{aligned}
$$

In this paper we focus exclusively on the balanced growth path. Plugging equation (8) into (6), we have

$$
y_{t}=\exp \left(\int_{0}^{1} q_{t}(j) d j \ln \gamma\right) L_{x}=\exp \left(\int_{0}^{t} \lambda_{v} d v \ln \gamma\right) L_{x}=Z_{t} L_{x}
$$

where $Z_{t} \equiv \exp \left(\int_{0}^{t} \lambda_{v} d v \ln \gamma\right)$ is the level of aggregate technology. The growth rate of $Z_{t}$ is

$$
g_{z}=\lambda_{t} \ln \gamma=\varphi l_{r, t} \ln \gamma
$$

which is linear in the share of labor employed by R\&D firms, as in standard Schumpeterian growth models (see e.g., Aghion and Howitt, 1998, ch. 2; Chu and Cozzi, 2014). On the balanced growth path, equation (18) shows that the growth rate of total output is $g_{y}=g_{z}+n$. Per capita consumption is $c_{t}=y_{t} / L_{t}$, implying that $c_{t}$ and $Z_{t}$ must grow at the same rate: $g_{c}=g_{z}$. Therefore, we have the balanced growth rate (the growth rate of per capita consumption or output) as

$$
\frac{\dot{c}}{c}=\varphi l_{r, t} \ln \gamma
$$

which is a decreasing function of the fertility rate, using (16).

Equations (20) and (16) indicate that there is no direct effect of the nominal interest rate on the balanced growth rate. This is the standard result with an inelastic labor supply and a CIA constraint on consumption only (see also Chu and Cozzi, 2014). With an inelastic labor supply, a higher nominal interest would not distort the labor supply through the consumption-leisure choice (i.e., the choice for leisure is absent). When the CIA constraint applies only on consumption (i.e., not on R\&D labor or manufacturing), a higher nominal interest would not distort the allocation of labor between manufacturing and R\&D, leaving the balanced growth rate unaffected. Therefore, in our model, there exists only an indirect effect of the nominal interest rate on the balanced growth rate, 
which is through its effect on fertility choice.

Thus, as long as we pin down the equilibrium fertility rate, we can solve for the balanced growth rate and then evaluate the effect of the nominal interest rate on the economy. Plugging the equilibrium conditions into (5) and using equation (3), we have

$$
\frac{\theta(1+i)}{n}=\frac{(\gamma-1)}{\gamma\left(\rho+\varphi l_{r}\right)}+\frac{1}{\xi \gamma l_{x}}+1
$$

where we have used the equilibrium conditions: $a_{t}=v_{t} / L_{t}=\frac{\Pi_{t}}{(\rho+\lambda) L_{t}}=\frac{\gamma-1}{\gamma} \frac{y_{t}}{(\rho+\lambda) L_{t}}$, which gives the first term in the right-hand side (RHS) of $(21) ; w_{t}=y_{t} /\left(\gamma L_{x}\right)$, which gives the second term in the RHS of (21); and $m_{t}=c_{t}$, which yields the third term in the RHS of (21).

Solving (14), (15), and (21) yields equilibrium fertility as the solution to the quadratic function

$$
\varphi n^{2}-[(1+i) \theta \varphi+\xi(\rho+\varphi)+\xi+\varphi] n+\xi \theta(\rho+\varphi)(1+i)=0 .
$$

After solving for the equilibrium fertility, equations (16) and (17) will solve manufacturing labor $l_{x}$ (and also R\&D labor $l_{r}$ ).

Solving (22), we have

$$
n^{*}=\frac{\Delta \pm \sqrt{\Delta^{2}-4 \varphi \xi \theta(\rho+\varphi)(1+i)}}{2 \varphi}
$$

where $\Delta=(1+i) \theta \varphi+\xi(\rho+\varphi)+\xi+\varphi$.

We rewrite $(21)$, using equation (14) to substitute for $\left(\rho+\varphi l_{r}\right)$ with $(\gamma-1) \varphi l_{x}$, as

$$
\gamma l_{x}=\frac{\xi+\varphi}{\xi \varphi} \frac{n}{\theta(1+i)-n}
$$

which we refer to as the $\mathrm{F}$ curve.

We also rewrite (17) as

$$
\gamma l_{x}=1-\frac{n}{\xi}+\frac{\rho}{\varphi}
$$

which we refer to as the $\mathrm{M}$ curve.

Now equations (24) and (25) govern the equilibrium of the economic system. The M curve is a downward-sloping straight line with $n$ on the horizontal axis, and the $\mathrm{F}$ curve is a hyperbola. As seen in Figure 1, the two curves must intersect twice. However, the higher fertility rate equilibrium naturally involves negative values of manufacturing labor $l_{x}$, which cannot be an equilibrium. Therefore, Figure 1 illustrates that our model has one unique equilibrium with fertility as the smaller root of (23). 


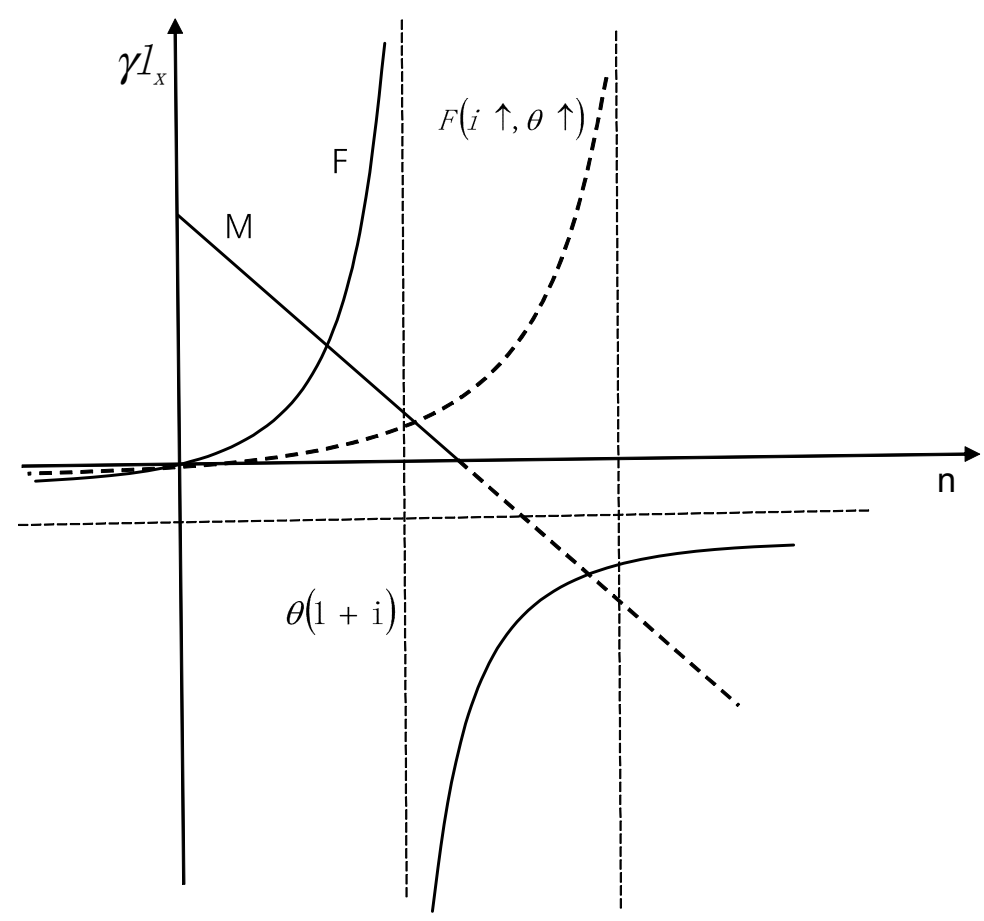

Figure 1. Steady-state equilibrium.

\subsection{Monetary Policy and Fertility}

Before we prove how an increase in the nominal interest rate affects the fertility rate mathematically, we can show it with Figure 1. Equation (25) shows that the M curve is not a function of the nominal interest rate, so the $M$ curve remains unchanged by an increase in the nominal interest rate. In contrast, Figure 1 illustrates that an increase in the nominal interest rate would shift the vertical asymptote of the hyperbola, which rotates the $\mathrm{F}$ curve rightwards. As a result, the equilibrium fertility rate increases and the manufacturing labor $l_{x}$ (and also $\mathrm{R} \& \mathrm{D}$ labor $l_{r}$ ) would decrease.

Mathematically, as illustrated above, our model has one unique equilibrium with fertility as the smaller root of (23), which is

$$
n^{*}=\frac{\Delta-\sqrt{\Delta^{2}-4 \varphi \xi \theta(\rho+\varphi)(1+i)}}{2 \varphi} .
$$

Therefore, we have

$$
\frac{\partial n^{*}}{\partial i}>\frac{1}{2 \varphi}\left(\frac{\partial \Delta}{\partial i}-\frac{\partial\left(\sqrt{\Delta^{2}}\right)}{\partial i}\right)=0 .
$$


The intuition behind equation (27) can be seen from equations (5) and (3). Equation (5) indicates that the marginal utility of fertility (i.e., $\theta / n_{t}$ ) equals the marginal cost of fertility (i.e., $\left.\left(a_{t}+w_{t} / \xi+m_{t}\right) /\left[c_{t}(1+i)\right]\right)$. The first and the second terms are the same as in Chu et al. (2013). That is, the first term is the asset-diluting effect of fertility, while the second is the foregone-wage effect of fertility. The third term is the real money balance-diluting effect. All else equal, according to equation (3), the marginal utility of consumption depends positively on the nominal interest rate. This is because the CIA constraint applies to consumption, which increases the effective price of consumption from 1 to $(1+i)$. Therefore, all else equal, a higher nominal interest rate decreases the right-hand side of equation (5) (i.e., the marginal cost of fertility), thereby increasing the fertility rate. In other words, the CIA constraint on consumption makes fertility cheaper relative to consumption, which in turn increases fertility.

The increase in fertility decreases the amount of labor supplied to production and R\&D (see equation (15)), which ends up decreasing the balanced growth rate. For instance, Li, Yi, and Zhang (2015) find a negative correlation between fertility and parental labor supply in OLS (ordinary least squares) estimation using Chinese data. Although they find no evidence of the negative effects of fertility on parental labor supply with twinning as a natural experiment, they suggest that the negative effects of fertility on parental labor supply are mitigated by the childcare provided by grandparents.

Proposition 1 In our model, the growth rate is a decreasing function of the nominal interest rate, while fertility is an increasing function of the nominal interest rate. Moreover, fertility is an increasing function of the inflation rate.

Proof: The first part is proven in the text. We now prove that fertility is also an increasing function of the inflation rate. On the balanced growth path, we have $\pi=i^{*}-g\left(i^{*}\right)-\rho$. Given an increase in the nominal interest rate, we have $g^{\prime}\left(i^{*}\right)<0$. This is because

$$
g^{\prime}\left(i^{*}\right)=-\frac{\varphi(\gamma-1) \ln \gamma}{\xi \gamma} \frac{\partial n^{*}}{\partial i}<0 .
$$

Therefore, there is a positive relationship between the nominal interest rate and the inflation rate. Taken together, we observe that fertility is an increasing function of the inflation rate. Q.E.D.

The intuition is already discussed. In the following we empirically test the prediction of our model. However, the nominal interest rate is difficult to observe across countries. In contrast, data on the rate of inflation is widely accessible and reliable. Because the inflation rate is determined by the nominal interest rate through the Fisher equation, we test the effect of the inflation rate on the fertility rate to check the validity of our theory and further evaluate the importance/magnitude of the channel that we emphasize. 
Before the regression analysis in Section 3, we would like to calibrate the model and simulate the quantitative effects of inflation on growth and social welfare to further increase the empirical appeals of the paper.

\subsection{Quantitative Analysis}

Our model has the following set of structural parameters $\{\rho, \gamma, \varphi, \theta, \xi\}$. We follow Chu, Ning, and Zhu (2017) to set the discount rate $\rho$ to a convential value of 0.04 and the step size of innovation $\gamma$ to 1.05. We need three conditions to pin down the values of $\{\varphi, \theta, \xi\}$. The first condition is the long-run GDP per capita growth of $2 \%$ in advanced countries (see Chu et al., 2017; Chu and Cozzi, 2014). The second condition is a $0.89 \%$ population growth rate in our data sample (see Section 3 for details). We need another condition. In Section 3, we will regress population growth on the inflation rate to test the predictions of our model. In this case we have $\frac{\partial n}{\partial \pi}=\frac{\partial n}{\partial i} \frac{\partial i}{\partial \pi}$. If we have $\frac{\partial i}{\partial \pi}$, we can recover $\frac{\partial n}{\partial i}=\frac{\partial n}{\partial \pi} / \frac{\partial i}{\partial \pi}$. However, as discussed above, the nominal interest rate set by the monetary authorities is difficult to observe across countries, and we do not have the necessary data. Nevertheless, our model has $i_{t}=\dot{M}_{t} / M_{t}+\rho$, and we have the data on monetary growth rates. As an alternative, we regress population growth on the money growth rate Money_growth, and we used the indicator - the broad money growth (annual \%) - in the Financial Sector section of the World Bank indicators (see Section 3 for details), controlling for fixed country effects and time effects. The regression results are as follows:

$$
\text { popn }_{i t}=0.35+0.0035(\text { Money_growth })_{i t}+\theta_{i}+T_{t}+\varepsilon_{i t},
$$

where $\theta_{i}$ and $T_{t}$ stand for the country fixed effects and year fixed effects, respectively. Therefore, we take the predicted value of 0.0035 for $\frac{\partial n}{\partial i}$. Now we pin down the values of $\{\varphi, \theta, \xi\}$ by solving the following three equations:

$$
\begin{gathered}
\frac{\xi+\varphi}{\xi \varphi} \frac{n}{\theta(1+i)-n}-\left(1-\frac{n}{\xi}+\frac{\rho}{\varphi}\right)=0 \\
g=\varphi\left(\frac{(\gamma-1)}{\gamma}\left(1-\frac{n}{\xi}+\frac{\rho}{\varphi}\right)-\frac{\rho}{\varphi}\right) \ln \gamma=0.02 \\
\frac{\partial n^{*}}{\partial i}=0.0035
\end{gathered}
$$

where $n^{*}$ is given in equation (26).

Solving equations (30)-(32) yields the values of $\{\varphi, \theta, \xi\}$ to be $\{21.96,1.22,0.0156\}$. To summarize, we pin down the parameter values $\{\rho, \gamma, \varphi, \theta, \xi\}$ as $\{0.04,1.05,21.96,1.22,0.0156\}$. Columns 1.1 and 1.2 of Table 1 report the calibration results for $i=0.096$ and $i=0$, respectively, where $i=0.096$ is our calculated sample value because $i=\pi+r=$ $\pi+\rho+g+n$ (our sample mean of inflation rate is 2.71\%). By reducing the nominal 
interest rate from $9.6 \%$ to $0 \%$, the growth gain is $0.12 \%$ annually, and the welfare gain $\Delta U$ is equivalent to a permanent increase in consumption of $3.14 \%$.

Figure 1 also illustrates some interesting comparative statics. For instance, the parameter $\theta$, which governs people's preference for children, works similarly with an increase in the nominal interest rate. We can also conduct some conterfactuals to evaluate the effect of a change in $\theta$ on growth and social welfare. Columns 1.3 and 1.4 present the counterfactual results of $\theta=4$ for $i=0.096$ and $i=0$, respectively. The results indicate that the growth and welfare effects depend on the size of $\theta$. An increase in $\theta$ means people prefer more children. In this case, the growth and welfare gains by reducing the nominal interest rate from $9.6 \%$ to $0 \%$ are much smaller. Additionally, one can observe that an increase in $\theta$ reduces the balanced growth rate. This is discussed above and illustrated in Figure 1. Comparing results in columns 1.1 and 1.3, when $\theta$ increases from 1.22 to 4 , growth decreases from $2 \%$ to $0.76 \%$. The loss in growth is large. The welfare loss is also large (not shown).

Table 1: Calibration Results

\begin{tabular}{|c|c|c|c|c|}
\hline & \multicolumn{4}{|c|}{ Column number } \\
\hline & 1.1 & 1.2 & 1.3 & 1.4 \\
\hline & $\multicolumn{4}{|c|}{\rho, \gamma, \varphi, \xi}=\{0.04,1.05,21.96,0.0156\}$ \\
\hline & \multicolumn{2}{|c|}{$\theta=1.22$} & \multicolumn{2}{|c|}{$\theta=4$} \\
\hline$i$ & $9.6 \%$ & $0 \%$ & $9.6 \%$ & $0 \%$ \\
\hline$l_{x}$ & 0.41 & 0.43 & 0.1778 & 0.1914 \\
\hline$l_{r}$ & 0.019 & 0.020 & 0.0071 & 0.0077 \\
\hline$n$ & $0.89 \%$ & $0.85 \%$ & $1.27 \%$ & $1.25 \%$ \\
\hline$g$ & $2.00 \%$ & $2.12 \%$ & $0.76 \%$ & $0.83 \%$ \\
\hline$\Delta U$ & $\mathrm{n} / \mathrm{a}$ & $3.14 \%$ & $\mathrm{n} / \mathrm{a}$ & $0.00 \%$ \\
\hline
\end{tabular}

Note: $i$ is the nominal interest rate.

$l_{x}$ and $l_{r}$ are the manufacturing labor and R\&D labor, respectively.

$n$ is the population growth rate, and $g$ is per capita growth rate.

$\Delta U$ is the welfare gain (equivalent to a permanent increase in consumption).

\section{Data}

\subsection{Empirical Specification}


Before we construct the variables, we present the empirical specification:

$$
\text { popn }_{i t}=\beta_{1} \pi_{i t}+\beta_{2}(\text { Controls })+\theta_{i}+T_{t}+\varepsilon_{i t},
$$

where $\mathrm{popn}_{i t}$ is the average annual growth rate of population during period $t$ for country $i$; $\pi_{i t}$ is the average annual inflation rate during period $t$ for country $i$. Controls are the other explanatory variables (explained below). $\theta_{i}$ and $T_{t}$ stand for the country fixed effects and year fixed effects, respectively.

To obtain more control variables in order to avoid the potential omitted variable bias, we include the following explanatory variables. The first one is infant mortality rate, denoted Mortality. It is included because a higher mortality rate would decrease the population growth rate. Moreover, we will check the robustness of our results by using the birth rate and the fertility rate as the dependent variables. In order to have offspring that survive to adulthood, people tend to give birth to more children when the expected rate of mortality is high.

The second control variable is related to human capital. Considering the qualityquantity trade-off for raising children (see e.g., Li, Zhang, and Zhu, 2008; Galor and Mountfold, 2008; Rosenzweig and Zhang, 2009), we include a human capital indicator, denoted Human. A higher level of human capital decreases the time devoted to raising more children, ultimately decreasing the population growth rate. For instance, Rosenzweig and Zhang (2009) find evidence of a significant trade-off between the number of children and child quality in China. Li, Zhang, and Zhu (2008) use data from the Chinese Population Census and find a negative effect of family size on children's education.

Additionally, more advanced countries tend to have lower population growth. That is, we control for per capita level of output. The last control variable is the physical capital investment rate, denoted $I / G D P$. It is included because investments may impact growth, thereby affecting population growth.

\subsection{Identification Strategy}

In aggregate level studies, there is always a possibility of endogeneity. That is, it is possible that there may be a feedback effect from population growth to the inflation rate. For instance, higher population growth might decrease economic growth (Chu et al., 2013) as bidirectional causality may exist between growth and inflation, as argued in the sizeable literature on the inflation-growth nexus (e.g., He and Zou, 2016, and references therein). Therefore, the OLS estimation would be biased.

In this paper we use IV estimation to deal with the potential endogeneity of the inflation rate. It is difficult to find a suitable instrument for the inflation rate. In another study we find that CBI has a significant effect on the inflation rate only in advanced 
countries. Therefore, we use $C B I$ as the instrument for the inflation rate. CBI changes slowly over time, which indicates that there may be no feedback effect from population growth to CBI.

Moreover, as discussed in the theoretical model, we have $i_{t}=M_{t} / M_{t}+\rho$. Combining with Proposition 1 indicates that the money growth rate would also impact the population growth rate. Therefore, to check the robustness of our results, we will also use the money growth rate as an additional instrument. With more instruments than endogenous variables, we can use the over-identifying tests to check the validity of the instruments, despite the fact that the tests are known to have little statistical power.

\subsection{Data Sample}

For some of the variables, we use World Bank indicators. For the rest of the control variables, we use the recent Penn World Table (PWT) 9.0 (explained by Feenstra et al., 2014). PWT 9.0 provides the most complete and most recent data for all the countries during 1950-2014. We exclude from our sample countries that do not have data on employment (the emp series in PWT 9.0) and/or human capital (the $h c$ series in PWT 9.0). This leaves us with 144 countries in the sample.

For the measure of CBI, we follow the recent study of Dincer and Eichengreen (2014). Dincer and Eichengreen (2014) do not report data on CBI for countries with the euro as their currency. Moreover, some countries in Dincer and Eichengreen (2014) do not have data on employment and/or human capital. Taken together, this leaves us with 68 countries.

Out of the 68 countries, 12 are advanced-namely, Australia, Canada, U.K., Iceland, Israel, Japan, the Republic of Korea, Norway, New Zealand, Singapore, Sweden, and the United States. As discussed above, in another study we find that CBI has a significant effect on the inflation rate only in advanced countries. Therefore, our final sample has 12 advanced countries.

Because the CBI sample in Dincer and Eichengreen (2014) covers 1998-2010, we use the sample 2000-2014. Following the common practice in the literature on empirical growth (e.g., Aghion et al., 2009), we take five-year averages of the data (unless indicated otherwise), yielding three sub-periods: 2000-2004, 2005-2009, and 2010-2014. The CBI data before each sup-period are used. That is, the CBI data (in Table 9 of Dincer and Eichengreen, 2014) in years 1999, 2004, and 2009 are used for sub-periods 20002004, 2005-2009, and 2010-2014, respectively. Therefore, our final sample consists of 12 countries during 2000-2014 (15 years), providing a balanced panel of 36 observations.

\subsection{Measuring the Population Growth and the Inflation Rate}

The recent PWT 9.0 provides the most complete and recent data on total population for 
all the countries during 1950-2014. We take the population data for our 12 advanced countries during 2000-2014. Because we are taking five-year averages of the data, we calculate the annual growth rate of the population during each sub-period, denoted popn. For instance, the average annual growth rate of population for sub-period 2000-2004 would be $[\log ($ population in 2004)- $\log$ (population in 2000)]/4.

To check the robustness of our results, we also use other measures of the dependent variable. For instance, we have used the birth rate and the fertility rate as the dependent variable. For the birth rate, we used the indicator - crude birth rate (per 1,000 people)in the Health section of the World Bank indicators, denoted Birth_rate. For the fertility rate, we used the indicator - total fertility rate (births per woman) - in the Health section of the World Bank indicators, denoted Fertility.

Following existing studies (e.g., Aghion et al., 2009), we measure the inflation rate $\pi$ as the percentage change in the consumer price index (CPI). The PWT 9.0 does not provide data on CPI. We acquire the CPI data from the International Financial Statistics (IFS) of the International Monetary Fund (IMF) to obtain the data on CPI for over 100 countries (including the 12 countries in our sample) during 1950-2015. Our results remain robust to the transformed measures of the inflation. For instance, in the literature on the CBI-inflation nexus, researchers also used the logarithm of (1+inflation rate) (see e.g., Dincer and Eichengreen, 2014). Our results remain robust to using the logarithm of $(1+$ inflation rate) as the measure of the inflation rate (results not reported, but available upon request).

\subsection{Measuring the Instruments}

The seminal study of Bade and Parkin (1988) was among the first to empirically investigate variations in the degree of CBI across countries. Following this, there emerged a large body of literature measuring CBI (see e.g., Alesina [1988], Cukierman, Webb, and Neyapti [1992], and Alesina and Summers [1993] for early studies, and Dincer and Eichengreen [2014] for recent contributions). We use the most recent data on CBI from Dincer and Eichengreen (2014) (DE hereafter). DE report updated measures of independence for more than 100 central banks during 1998-2010. DE follow Cukierman, Webb, and Neyapti (1992) (CWN hereafter) but add other aspects of CBI emphasized in the subsequent literature to measure CBI. Specifically, DE use the 16 criteria employed by CWN and 8 additional criteria (24 in total, see DE, 218-219 for details).

DE first aggregate their 24 criteria into 9 criteria as follows: "(1) The five variables regarding appointment of the $\mathrm{CEO}$ are aggregated into one using equal weights; (2) the four variables under policy formulation are aggregated into one using equal weights; (3) the objectives criterion stands on its own as number 3 ; $(4-7)$ the first four criteria on

limits on lending are each treated as a separate variable, (8) the last four criteria on 
limits on lending are aggregated into a single variable using equal weights; and (9) the criteria regarding board members is treated as a single variable" (DE, p. 219). Each criterion is coded on a scale of 0 (lowest degree of CBI) to 1 (highest degree of CBI). The final aggregate measure on CBI also ranges from 0 to 1 (lowest and highest degrees of CBI, respectively).

We use the unweighted average of the nine aggregated variables (i.e., CBIU in Table 9 of DE) to measure CBI, denoted CBI. As discussed, the CBI data in years 1999, 2004, and 2009 are used for sub-periods 2000-2004, 2005-2009, and 2010-2014, respectively.

As CBI does change over time, we report the results from panel data regressions. The advantage of panel data regression is that it allows us to control for fixed country effects. We have checked the results from cross-country regressions, and we have found that they differ a lot from those of panel data regressions. Therefore, cross-country regressions without controlling for country fixed effects would suffer from the bias from omitting such effects.

For the money growth rate Money_growth, we used the indicator-broad money growth (annual \%) - in the Financial Sector section of the World Bank indicators. We then take five-year averages of the data.

\subsection{Measuring Control Variables}

For the infant mortality rate (Mortality), we have used the World Bank indicators to get the data. We used the indicator - infant mortality rate per 1,000 live births - in the Health section of the World Bank indicators.

According to Feenstra, Inklaar, and Timmer (2015, p. 3157), "If the sole object is to compare the growth performance of economies, we would recommend using the $R G D P^{N A}$ series (and this is closest to earlier versions of PWT)." Thus, we use the $R G D P^{N A}$ series to measure real GDP. Dividing the $R G D P^{N A}$ series by the emp series in PWT 9.0 would yield real GDP per employment that measures per capita level of output in our study. To mitigate its potential endogeneity problem, we use initial real GDP per employment (i.e., $\left.(G D P / e m p)_{t-1}\right)$ that takes the value of the previous year. The human capital indicator Human is measured by the $h c$ series in PWT 9.0. The physical capital investment rate $I / G D P$ is measured by the $c s h \_i$ series in PWT 9.0. Table 2 presents the summary statistics of the final data.

[Table 2 Here]

\section{Estimation Results}

\subsection{Least Squares Dummy Variables Estimation}


We first use the LSDV (least squares dummy variables) estimation (i.e., OLS estimation that includes 12 country dummies and 3 time dummies) and present the results in Table 3 .

According to regression 3.1 in Table 3, when the population growth rate (popn) is the dependent variable, the estimated coefficient on the inflation rate is negative, which is insignificant at the $10 \%$ level. That is, a higher level of inflation rate is insignificantly and negatively associated with population growth in the 12 advanced economies during 2000-2014. The estimated coefficient on the infant mortality rate (Mortality) is negative as expected, which is insignificant at the $10 \%$ level. The estimated coefficient on the human capital indicator $(\ln ($ Human $))$ is negative and significant at the $10 \%$ level, as expected. The estimated coefficient on physical capital investment rate $(\ln (I / G D P))$ is positive and significant at the $5 \%$ level. The estimated coefficient on the income level $\left(\ln (G D P / e m p)_{t-1}\right)$ is positive and insignificant. The $\mathrm{R}$-squared is 0.95 , meaning our empirical specification fits the cross-country population data quite well.

It is very possible that the observations are independent across groups (i.e., countries) but not necessarily within groups. Therefore, we allow for intragroup correlation (i.e., the correlation of observations over time for each country). This is reasonable because the population growth rate for each country may be correlated over time. However, it is hard to support that the population growth rates across countries are correlated. For example, the population growth rates of Japan may be correlated over time, but they would be uncorrelated with those of the United States. Specifically, we cluster the time dummies and use cluster-robust standard errors. The results are presented in regress 3.2 of Table 3. The results remain similar to those in regression 3.1.

According to regression 3.3 in Table 3, when the birth rate (Birth_rate) is the dependent variable, the estimated coefficient on the inflation rate is positive as expected, which is insignificant at the $10 \%$ level. The estimated coefficients on the other control variables all become insignificant. This is why we believe the population growth rate may be more suitable for our purpose. According to regression 3.5 in Table 3, when the fertility rate (Fertility) is the dependent variable, the estimated coefficient on the inflation rate is positive as expected, which is insignificant at the $10 \%$ level. The estimated coefficients on the other control variables all become insignificant. Regressions 3.4 and 3.6 indicate that the results remain similar when we use cluster-robust standard errors.

[Table 3 Here]

\subsection{Estimation}

As discussed, there is always a possibility of endogeneity (either from omitting important variables or from reverse causality) in aggregate-level studies. We have used CBI and 
money growth as instruments. We use the most efficient 2SLS (two-stage least squares) estimation. Additionally, as discussed above, we allow for intragroup correlation and use cluster-robust standard errors.

The corresponding 2SLS estimation results for LSDV regressions 3.2, 3.4, and 3.6 are presented in Tables 4 and 5. Table 4 presents the first-stage results, and the corresponding second-stage results are in Table 5. Regression 4.1 of Table 4 reports the first-stage results with $\mathrm{CBI}$ as the sole instrument. The results indicate that the estimated coefficient on the instrument CBI is significant at the $1 \%$ level, indicating that CBI has a significant effect on the inflation rate in advanced countries during 2000-2014. In other words, the instrument is strong.

[Table 4 Here]

Table 5 presents the corresponding second-stage results of the 2SLS estimation. According to regression 5.1 in Table 5, when the population growth rate (popn) is the dependent variable, the estimated coefficient on the inflation rate becomes positive, which is significant at the $1 \%$ level. That is, a higher level of inflation rate significantly increases population growth in the 12 advanced economies during 2000-2014. The estimated coefficient on the infant mortality rate (Mortality) remains negative as expected, which becomes significant at the $1 \%$ level. The estimated coefficient on the human capital indicator $(\ln ($ Human $))$ remains negative and becomes significant at the $1 \%$ level. The estimated coefficient on physical capital investment rate $(\ln (I / G D P))$ remains positive and significant at the $1 \%$ level. The estimated coefficient on the income level $\left(\ln (G D P / e m p)_{t-1}\right)$ remains insignificant.

The results remain similar when we use both CBI and money growth as the instruments, as indicated in regression 5.2 of Table 5 . Because robust tests of overidentifying restrictions after 2SLS estimation are not available with cluster-robust standard errors, we have used robust standard errors (i.e., we allow for both intragroup and intergroup correlations). The results are not reported but are available upon request. Nevertheless, the estimated coefficient on the inflation rate remains positive and significant at the $5 \%$ level. Moreover, the over-identification test yields a p-value 0.86, meaning the instruments are valid.

According to regression 5.3 in Table 5, when the birth rate (Birth_rate) is the dependent variable, the estimated coefficient on the inflation rate remains positive and becomes significant at the $1 \%$ level. The estimation results on the other control variables remain similar to those in regression 5.1. Regression 5.4 of Table 5 indicates that the results remain similar with both CBI and money growth as the two instruments.

According to regression 5.5 in Table 5, when the fertility rate (Fertility) is the dependent variable, the estimated coefficient on the inflation rate remains positive and becomes 
significant at the $10 \%$ level. The estimation results on the other control variables remain similar to those in regression 5.1. Regression 5.6 of Table 5 indicates that the estimated coefficient on the inflation rate remains positive and becomes significant at the $5 \%$ level with both CBI and money growth as the two instruments.

[Table 5 Here]

Andrews and Stock (2005) state that now the common approach is to use 2SLS if instruments are strong and to adopt a robust strategy if instruments are weak. With weak instruments, Stock and Yogo (2002) show that LIML (limited-information maximum likelihood) estimation is far superior to 2SLS. We have checked the robustness of our results with the LIML estimation. The corresponding second-stage results of the LIML estimation are presented in Table 6. One can observe that our results remain almost identical to those in Table 5.

\section{[Table 6 Here]}

Therefore, the positive, significant effect of inflation on population growth is robust and causal. Using regression 5.1, we find that an increase of 1 percentage point in annual inflation would bring an increase of 0.06 percentage point in the annual growth of the total population. Given the average annual inflation rate of $2.71 \%$ in our data sample, inflation explains $0.17 \%$ of the annual growth in the total population (which is around $20 \%$ of the average $0.89 \%$ annual growth rate in the total population in the 12 advanced economies during 2000-2014). Therefore, the magnitude of the estimated effect of inflation on total population growth is large in the 12 advanced economies during 2000-2014.

\section{Conclusion}

This study explores the growth effects of monetary policy in a scale-invariant Schumpeterian growth model with endogenous fertility. We model money demand via a CIA constraint on consumption. We find a positive effect of an increase in the nominal interest rate on fertility. A higher nominal interest rate and thereby a higher inflation rate via the CIA constraint on consumption makes consumption more expensive relative to fertility, ending up in increasing fertility. The increase in fertility decreases labor supplied to production and $\mathrm{R} \& \mathrm{D}$, which in turn decreases long-run growth. In contrast, with an inelastic labor supply and the CIA constraint on consumption, fertility and growth do not depend on the inflation rate with exogenous fertility.

We calibrate the model to estimate the growth and welfare effects of a change in the nominal interest rate. We find that long-run growth increases $0.12 \%$ by reducing 
the nominal interest rate from $9.6 \%$ (the sample mean, elaborated below) to $0 \%$. The corresponding welfare gain is equivalent to a permanent increase in consumption of $3.14 \%$. As a counterfactual, we find that the growth and welfare losses are smaller when people prefer more children. Additionally, there are substantial growth and welfare losses when people's preference for children increases, all else being equal.

As an empirical test, we build panel data for 12 advanced countries during 2000-2014. We use the degree of central bank independence and money growth as the instruments for inflation. We find the following. The effect of inflation on population growth is positive and significant in IV estimation. Our results remain robust to using the birth rate and fertility rate as the dependent variables. Thus, our empirical findings provide support for our theory. Moreover, our empirical evaluation indicates that the magnitude of the effect of monetary policy on population growth is large and significant. Therefore, our study helps us to understand the long-run dynamics of the total population. Our study also has rich policy implications if one country wants to manipulate its population growth in an ageing era. In-depth study in this area is important, and we leave it to future researchers.

\section{References}

[1] Andrews, D., and Stock, J.H. 2005. "Inference with Weak Instruments." Cowles Foundation Discussion Paper No. 1530.

[2] Aghion, P., Bacchetta, P., Ranciere, R., and Rogoff, K. 2009. "Exchange rate volatility and productivity growth: The role of financial development," Journal of Monetary Economics 56(4): 494-513.

[3] Aghion, P., and Howitt, P. 1998. Endogenous Growth Theory, Cambridge, MA: the MIT Press.

[4] Alesina, A. 1988. "Macroeconomics and Politics." In NBER Macroeconomics Annual, edited by Stanley Fischer: 17-52. Cambridge, Mass.: MIT Press.

[5] Alesina, A., and Summers, L. 1993. "Central Bank Independence and Macroeconomic Performance: Some Comparative Evidence." Journal of Money, Credit and Banking 25(2): 151-62.

[6] Bade, R. and Parkin, M. 1988. "Central Bank Laws and Monetary Policy." mimeo, University of Western Ontario.

[7] Chen, H., 2015. "Innovation and imitation in a product-cycle model with FDI and cash-in-advance constraints." MPRA Paper No. 65744. 
[8] Chu, A. and Cozzi, G. 2014. "R\&D and economic growth in a cash-in-advance economy." International Economic Review, 55: 507-524.

[9] Chu, A., Cozzi, G., Fan, H., Furukawa, Y. \& Liao, C. 2018. "Innovation and Inequality in a Monetary Schumpeterian Model with Heterogeneous Households and Firms." MPRA paper 84711.

[10] Chu, A., Cozzi, G., Furukawa, Y., and Liao, C. 2017. "Inflation and economic growth in a Schumpeterian model with endogenous entry of heterogeneous firms," European Economic Review 98(C): 392-409.

[11] Chu, A., Cozzi, G., Lai, C., and Liao, C. 2015. "Inflation, R\&D and growth in an open economy." Journal of International Economics, 96, 360-374.

[12] Chu, A., Cozzi, G., and Liao, C. 2013. "Endogenous fertility and human capital in a Schumpeterian growth model," Journal of Population Economics 26(1): 181-202.

[13] Chu, A., Furukawa, Y., and Ji, L. 2016. "Patents, R\&D Subsidies and Endogenous Market Structure in a Schumpeterian Economy," Southern Economic Journal 82(3): 809-25.

[14] Chu, A., Ning, L., and Zhu, D. 2017. "Human Capital and Innovation in a Monetary Schumpeterian Growth Model." Macroeconomic Dynamics (forthcoming).

[15] Cukierman, A., Webb, S., and Neyapti, B. 1992. "Measuring the Independence of Central Banks and Its Effect on Policy Outcomes." World Bank Economic Review 6(3): 353-98.

[16] Davies, J. and Zhang, J. 1997. "The effects of gender control on fertility and children's consumption," Journal of Population Economics 10(1): 67-85.

[17] Dincer, N.N. and Eichengreen, B. 2014. "Central Bank Transparency and Independence: Updates and New Measures," International Journal of Central Banking 10(1): 189-253.

[18] Feenstra, R., Inklaar, R., and Timmer, M. 2015. "The Next Generation of the Penn World Table," American Economic Review 105(10): 3150-3182.

[19] Frankel, J., and Romer, D. 1999. "Does Trade Cause Growth?" American Economic Review 89(3): 379-399.

[20] Galor, O., and Mountfold, A. 2008. "Trading Population for Production: Theory and Evidence," Review of Economic Studies, 75: 1143-79. 
[21] He, Q. 2015. “A Monetary Variety-Expanding Growth Model with a Cash-in-Advance Constraint on Manufacturing." Economics Bulletin 35(1): 571-579.

[22] He, Q. and Zou, H-F. 2016. "Does Inflation Cause Growth in the Reform-era China? Theory and Evidence." International Review of Economics and Finance 45: 470-484.

[23] Huang, C., Chang, J., and Ji, L., 2015. "Inflation, market structure, and innovationdriven growth with various cash constraints." Working paper.

[24] Laincz, C. and Peretto, P. 2006. "Scale effects in endogenous growth theory: An error of aggregation not specification," Journal of Economic Growth, 11(3): 263-88.

[25] Li, H., Yi, J., and Zhang, J. 2015. "Fertility, Household Structure, and Parental Labor Supply: Evidence from Rural China," IZA Discussion Papers 9342, Institute for the Study of Labor (IZA).

[26] Li, H., Zhang, J., and Zhu, Y. 2008. "The quantity-Quality trade-Off of children In a developing country: Identification using chinese twins," Demography 45(1): 223-43.

[27] Marquis, M. and Reffett, K. 1994. "New technology spillovers into the payment system." Economic Journal, 104, 1123-1138.

[28] Nishimura, K. and Zhang, J. 1992. "Pay-as-you-go public pensions with endogenous fertility." Journal of Public Economics 48(2): 239-58.

[29] Rosenzweig, M. and Zhang, J. 2009. "Do Population Control Policies Induce More Human Capital Investment? Twins, Birth Weight and China's "One-Child" Policy," Review of Economic Studies 76(3): 1149-74.

[30] Stock, J.H., and Yogo, M. 2002: "Testing for Weak Instruments in Linear IV Regression." NBER Technical Working Paper No. 284.

[31] Strulik, H. and Weisdorf, J. 2008. "Population, food, and knowledge: a simple unified growth theory," Journal of Eoconomic Growth 13: 195-216. 


\section{APPENDIX: HOUSEHOLD'S DYNAMIC OPTIMIZATION}

We show the steps of solving the household's dynamic optimization problem using Hamiltionian. Household's Hamiltonian function is

$H_{t}=\ln c_{t}+\theta \ln n_{t}+\mu_{t}\left[\left(r_{t}-n_{t}\right) a_{t}+w_{t}\left(1-\frac{n_{t}}{\xi}\right)-c_{t}-\left(\pi_{t}+n_{t}\right) m_{t}+\tau_{t}\right]+v_{t}\left(m_{t}-c_{t}\right)$.

The first-order conditions include

$$
\begin{aligned}
\frac{\partial H_{t}}{\partial c_{t}} & =\frac{1}{c_{t}}-\mu_{t}-v_{t}=0, \\
\frac{\partial H_{t}}{\partial n_{t}} & =\frac{\theta}{n_{t}}-\mu_{t}\left[a_{t}+\frac{w_{t}}{\xi}+m_{t}\right]=0, \\
\frac{\partial H_{t}}{\partial a_{t}} & =\mu_{t}\left(r_{t}-n_{t}\right)=\rho \mu_{t}-\dot{\mu}_{t}, \\
\frac{\partial H_{t}}{\partial m_{t}} & =-\mu_{t}\left(\pi_{t}+n_{t}\right)+v_{t}=\rho \mu_{t}-\dot{\mu}_{t} .
\end{aligned}
$$

Combining (36) and (37) yields $v_{t}=\mu_{t}\left(r_{t}+\pi_{t}\right)=\mu_{t} i_{t}$, where $i_{t}$ is the nominal interest rate. Plugging this condition into (34) yields

$$
\frac{1}{c_{t}}=\mu_{t}\left(1+i_{t}\right)
$$

which is (3) in the main text.

Rewriting (36) as

$$
-\frac{\dot{\mu_{t}}}{\mu_{t}}=r_{t}-n_{t}-\rho
$$

yields the intertemporal optimality condition (4) in the main text.

Equation (35) is the optimal condition for fertility in equation (5) in the main text. 
Table 2: Descriptive Statistics

\begin{tabular}{lccccc}
\hline \hline & Observations & Mean & Standard deviation & Minimum & Maximum \\
\hline popn (\%) & 36 & 0.89 & 0.56 & -0.08 & 2.21 \\
Birth_rate & 36 & 1.82 & 0.45 & 1.16 & 3.03 \\
Fertility & 36 & 12.72 & 3.20 & 8.24 & 21.52 \\
Mortality & 36 & 3.98 & 1.41 & 1.82 & 6.96 \\
$\pi(\%)$ & 36 & 2.71 & 1.88 & -0.52 & 8.19 \\
$\ln (\text { GDP/emp })_{t-1}$ & 36 & 11.27 & 0.28 & 10.77 & 11.99 \\
$\ln ($ Human $)$ & 36 & 1.22 & 0.08 & 0.99 & 1.31 \\
$\ln ($ I/GDP $)$ & 36 & 3.24 & 0.21 & 2.81 & 3.68 \\
& & & & & \\
\hline \hline
\end{tabular}

Note: the data are from the PWT 9.0 (unless indicated otherwise), covering 12 countries during 2000-2014. $\pi$ is the inflation rate using the CPI data of IFS of IMF.

Birth_rate, Fertility, and Mortality are the crude birth rate (per 1,000 people), the total fertility rate (births per woman), and the infant mortality rate (per 1,000 live births), respectively. The data on birth_rate, fertility, and Mortality are from the World Bank indicators.

GDP/emp is real GDP per employment (in 2011 us\$). Human measures human capital. $I / G D P$ is the investment rate.

The variables are are multiplied by 100 before taking logarithms. 
Table 3. LSDV Regressions

\begin{tabular}{|c|c|c|c|c|c|c|}
\hline \multirow[b]{4}{*}{ Indep. Variable } & \multicolumn{6}{|c|}{ Regression number } \\
\hline & 3.1 & 3.2 & 3.3 & 3.4 & 3.5 & 3.6 \\
\hline & \multicolumn{6}{|c|}{ Dependent variable as } \\
\hline & popn & popn & Birth_rate & Birth_rate & Fertility & Fertility \\
\hline \multirow{2}{*}{$\pi$} & -0.003 & -0.003 & 0.01 & 0.01 & 0.003 & 0.003 \\
\hline & $(0.03)$ & $(0.03)$ & $(0.10)$ & $(0.02)$ & $(0.01)$ & $(0.005)$ \\
\hline \multirow{2}{*}{ Mortality } & -0.12 & -0.12 & 0.32 & 0.32 & 0.02 & 0.02 \\
\hline & $(0.18)$ & $(0.13)$ & $(0.56)$ & $(0.45)$ & $(0.07)$ & $(0.05)$ \\
\hline \multirow{2}{*}{$\ln ($ Human $)$} & $-3.05^{*}$ & $-3.05^{* * *}$ & -8.20 & -8.20 & -1.12 & -1.12 \\
\hline & $(1.04)$ & $(0.30)$ & $(5.04)$ & $(4.14)$ & $(0.68)$ & $(0.56)$ \\
\hline \multirow{2}{*}{$\ln (I / G D P)$} & $0.72^{* *}$ & $0.72^{* *}$ & 1.14 & 1.14 & 0.16 & 0.16 \\
\hline & $(0.27)$ & $(0.27)$ & $(0.82)$ & $(0.38)$ & $(0.11)$ & $(0.07)$ \\
\hline \multirow{2}{*}{$\ln \left(\frac{G D P}{e m p}\right)_{t-1}$} & 0.02 & 0.02 & -1.80 & -1.80 & 0.01 & 0.01 \\
\hline & $(1.28)$ & $(0.55)$ & $(3.92)$ & $(1.12)$ & $(0.53)$ & $(0.20)$ \\
\hline Time FE & YES & YES & YES & YES & YES & YES \\
\hline Country FE & YES & YES & YES & YES & YES & YES \\
\hline $\mathrm{R}^{2}$ & 0.95 & 0.95 & 0.98 & 0.98 & 0.99 & 0.99 \\
\hline Observations & 36 & 36 & 36 & 36 & 36 & 36 \\
\hline
\end{tabular}

Note: $\pi$ is the inflation rate using the CPI data of IFS of IMF.

popn is the average annual growth rate of total population.

Birth_rate, Fertility, and Mortality are the crude birth rate (per 1,000 people), the total

fertility rate (births per woman), and the infant mortality rate (per 1,000 live births), respectively.

The data on Birth_rate, Fertility, and Mortality are from the World Bank indicators.

Human is human capital. I/GDP is investment rate.

GDP/emp is real GDP (in 2011 us \$) per employment.

***Significant at the 0.01 level, ${ }^{* *}$ at the 0.05 level, ${ }^{*}$ at the 0.10 level

(3.1, 3.3, 3.5: standard errors in parentheses)

(3.2, 3.4, 3.6: cluster-robust standard errors in parentheses) 
Table 4. 2SLS Regressions

First-stage results (first-stage dep. vari.: $\pi$ )

\begin{tabular}{|c|c|c|}
\hline \multirow[b]{2}{*}{ Indep. Variable } & \multicolumn{2}{|c|}{ Regression number } \\
\hline & 4.1 & 4.2 \\
\hline \multirow{2}{*}{$C B I$} & $6.42^{* * *}$ & $6.42^{* * *}$ \\
\hline & $(1.70)$ & $(1.74)$ \\
\hline \multirow{2}{*}{ Money_growth } & & -0.01 \\
\hline & & $(0.06)$ \\
\hline \multirow{2}{*}{ Mortality } & $2.84^{*}$ & $2.87^{*}$ \\
\hline & $(1.36)$ & $(1.62)$ \\
\hline \multirow{2}{*}{$\ln ($ Human $)$} & -11.94 & -12.17 \\
\hline & $(12.86)$ & $(14.09)$ \\
\hline \multirow{2}{*}{$\ln (I / G D P)$} & -1.84 & -1.79 \\
\hline & $(1.79)$ & $(2.04)$ \\
\hline \multirow{2}{*}{$\ln \left(\frac{G D P}{e m p}\right)_{t-1}$} & 15.58 & 15.69 \\
\hline & $(9.50)$ & $(10.09)$ \\
\hline Time FE & YES & YES \\
\hline Country FE & YES & YES \\
\hline $\mathrm{R}^{2}$ & 0.80 & 0.80 \\
\hline Observations & 36 & 36 \\
\hline
\end{tabular}

Note: $\pi$ is the inflation rate using the CPI data of IFS of IMF.

$C B I$ is the degree of central bank independence.

Money_growth is the broad money growth from the World Bank indicators. Mortality is the infant mortality rate (per 1,000 live births) from the World Bank indicators.

Human is human capital. $I / G D P$ is investment rate.

GDP/emp is real GDP (in 2011 us \$) per employment.

${ }^{* * *}$ Significant at the 0.01 level, ${ }^{* *}$ at the 0.05 level, ${ }^{*}$ at the 0.10 level

(cluster-robust standard errors in parentheses) 
Table 5. 2SLS Regressions (second-stage results)

\begin{tabular}{|c|c|c|c|c|c|c|}
\hline \multirow[b]{4}{*}{ Indep. Variable } & \multicolumn{6}{|c|}{ Regression number } \\
\hline & 5.1 & 5.2 & 5.3 & 5.4 & 5.5 & 5.6 \\
\hline & \multicolumn{6}{|c|}{ Dependent variable as } \\
\hline & popn & popn & Birth_rate & Birth_rate & Fertility & Fertility \\
\hline$\pi$ & $\begin{array}{c}0.06^{* * *} \\
(0.01)\end{array}$ & $\begin{array}{c}0.06^{* * *} \\
(0.01)\end{array}$ & $\begin{array}{c}0.07^{* * *} \\
(0.03)\end{array}$ & $\begin{array}{c}0.08^{* * *} \\
(0.02)\end{array}$ & $\begin{array}{l}0.007^{*} \\
(0.004)\end{array}$ & $\begin{array}{l}0.008^{* *} \\
(0.004)\end{array}$ \\
\hline Mortality & $\begin{array}{c}-0.31^{* * *} \\
(0.11)\end{array}$ & $\begin{array}{c}-0.32^{* * *} \\
(0.11)\end{array}$ & $\begin{array}{c}0.15 \\
(0.23)\end{array}$ & $\begin{array}{c}0.13 \\
(0.23)\end{array}$ & $\begin{array}{l}0.004 \\
(0.03)\end{array}$ & $\begin{array}{l}0.001 \\
(0.03)\end{array}$ \\
\hline $\ln ($ Human $)$ & $\begin{array}{c}-2.32^{* * *} \\
(0.75)\end{array}$ & $\begin{array}{c}-2.33^{* * *} \\
(0.74)\end{array}$ & $\begin{array}{c}-7.59^{* * *} \\
(1.36)\end{array}$ & $\begin{array}{c}-7.50^{* * *} \\
(1.33)\end{array}$ & $\begin{array}{c}-1.08^{* * *} \\
(0.23)\end{array}$ & $\begin{array}{c}-1.07^{* * *} \\
(0.23)\end{array}$ \\
\hline $\ln (I / G D P)$ & $\begin{array}{c}0.82^{* * *} \\
(0.12)\end{array}$ & $\begin{array}{c}0.82^{* * *} \\
(0.12)\end{array}$ & $\begin{array}{c}1.23^{* * *} \\
(0.18)\end{array}$ & $\begin{array}{c}1.24^{* * *} \\
(0.16)\end{array}$ & $\begin{array}{c}0.17^{* * *} \\
(0.04)\end{array}$ & $\begin{array}{c}0.17^{* * *} \\
(0.03)\end{array}$ \\
\hline $\ln \left(\frac{G D P}{e m p}\right)_{t-1}$ & $\begin{array}{l}-1.23 \\
(1.08)\end{array}$ & $\begin{array}{l}-1.22 \\
(1.08)\end{array}$ & $\begin{array}{l}-2.85 \\
(1.49)\end{array}$ & $\begin{array}{c}-3.00^{* *} \\
(1.48)\end{array}$ & $\begin{array}{l}-0.06 \\
(0.22)\end{array}$ & $\begin{array}{l}-0.08 \\
(0.21)\end{array}$ \\
\hline Time FE & YES & YES & YES & YES & YES & YES \\
\hline Country FE & YES & YES & YES & YES & YES & YES \\
\hline $\mathrm{R}^{2}$ & 0.93 & 0.93 & 0.98 & 0.98 & 0.99 & 0.99 \\
\hline Observations & 36 & 36 & 36 & 36 & 36 & 36 \\
\hline
\end{tabular}

Note: $\pi$ is the inflation rate using the CPI data of IFS of IMF.

popn is the average annual growth rate of total population.

Birth_rate, Fertility, and Mortality are the crude birth rate (per 1,000 people), the total fertility rate (births per woman), and the infant mortality rate (per 1,000 live births), respectively. The data on Birth_rate, Fertility, and Mortality are from the World Bank indicators.

Human is human capital. I/GDP is investment rate.

GDP/emp is real GDP (in 2011 us \$) per employment.

Instruments used: 5.1, 5.3, and 5.5: CBI; 5.2, 5.4, and 5.6: CBI and Money_growth.

***Significant at the 0.01 level, ${ }^{* *}$ at the 0.05 level, $*$ at the 0.10 level

(cluster-robust standard errors in parentheses) 
Table 6. LIML Regressions (second-stage results)

\begin{tabular}{|c|c|c|c|c|c|c|}
\hline \multirow[b]{4}{*}{ Indep. Variable } & \multicolumn{6}{|c|}{ Regression number } \\
\hline & 6.1 & 6.2 & 6.3 & 6.4 & 6.5 & 6.6 \\
\hline & \multicolumn{6}{|c|}{ Dependent variable as } \\
\hline & popn & popn & Birth_rate & Birth_rate & Fertility & Fertility \\
\hline$\pi$ & $\begin{array}{c}0.06^{* * *} \\
(0.01)\end{array}$ & $\begin{array}{c}0.06^{* * *} \\
(0.01)\end{array}$ & $\begin{array}{c}0.07^{* * *} \\
(0.03)\end{array}$ & $\begin{array}{c}0.09^{* * *} \\
(0.02)\end{array}$ & $\begin{array}{l}0.007^{*} \\
(0.004)\end{array}$ & $\begin{array}{l}0.008^{* *} \\
(0.004)\end{array}$ \\
\hline Mortality & $\begin{array}{c}-0.31^{* * *} \\
(0.11)\end{array}$ & $\begin{array}{c}-0.32^{* * *} \\
(0.11)\end{array}$ & $\begin{array}{c}0.15 \\
(0.23)\end{array}$ & $\begin{array}{c}0.10 \\
(0.22)\end{array}$ & $\begin{array}{l}0.004 \\
(0.03)\end{array}$ & $\begin{array}{c}-0.001 \\
(0.03)\end{array}$ \\
\hline $\ln ($ Human $)$ & $\begin{array}{c}-2.32^{* * *} \\
(0.75)\end{array}$ & $\begin{array}{c}-2.33^{* * *} \\
(0.74)\end{array}$ & $\begin{array}{c}-7.59^{* * *} \\
(1.36)\end{array}$ & $\begin{array}{c}-7.39^{* * *} \\
(1.23)\end{array}$ & $\begin{array}{c}-1.08^{* * *} \\
(0.23)\end{array}$ & $\begin{array}{c}-1.06^{* * *} \\
(0.22)\end{array}$ \\
\hline $\ln (I / G D P)$ & $\begin{array}{c}0.82^{* * *} \\
(0.12)\end{array}$ & $\begin{array}{c}0.82^{* * *} \\
(0.12)\end{array}$ & $\begin{array}{c}1.23^{* * *} \\
(0.18)\end{array}$ & $\begin{array}{c}1.26^{* * *} \\
(0.15)\end{array}$ & $\begin{array}{c}0.17^{* * *} \\
(0.04)\end{array}$ & $\begin{array}{c}0.17^{* * *} \\
(0.03)\end{array}$ \\
\hline $\ln \left(\frac{G D P}{e m p}\right)_{t-1}$ & $\begin{array}{l}-1.23 \\
(1.08)\end{array}$ & $\begin{array}{l}-1.23 \\
(1.08)\end{array}$ & $\begin{array}{l}-2.85 \\
(1.49)\end{array}$ & $\begin{array}{c}-3.19^{* *} \\
(1.55)\end{array}$ & $\begin{array}{l}-0.06 \\
(0.22)\end{array}$ & $\begin{array}{l}-0.10 \\
(0.23)\end{array}$ \\
\hline Time FE & YES & YES & YES & YES & YES & YES \\
\hline Country FE & YES & YES & YES & YES & YES & YES \\
\hline $\mathrm{R}^{2}$ (centered) & 0.93 & 0.93 & 0.98 & 0.98 & 0.99 & 0.99 \\
\hline Observations & 36 & 36 & 36 & 36 & 36 & 36 \\
\hline
\end{tabular}

Note: $\pi$ is the inflation rate using the CPI data of IFS of IMF.

popn is the average annual growth rate of total population.

Birth_rate, Fertility, and Mortality are the crude birth rate (per 1,000 people), the total fertility rate (births per woman), and the infant mortality rate (per 1,000 live births), respectively. The data on Birth_rate, Fertility, and Mortality are from the World Bank indicators.

Human is human capital. I/GDP is investment rate.

GDP/emp is real GDP (in 2011 us \$) per employment.

Instruments used: 6.1, 6.3, and 6.5: CBI; 6.2, 6.4, and 6.6: CBI and Money_growth.

***Significant at the 0.01 level, ${ }^{* *}$ at the 0.05 level, $*$ at the 0.10 level

(cluster-robust standard errors in parentheses) 